\title{
AMBIENTE VIRTUAL DE APRENDIZAGEM COMO FERRAMENTA PARA O ESTUDO EXTRA-CLASSE E EDUCAÇÃO CONTINUADA
}

\author{
Denise Costa Dias ${ }^{1}$, Débora Ignácio Alves ${ }^{2}$, Luciana Magnani Fernandes ${ }^{1}$, Lorena Moraes Gueten Gemelli²
}

\begin{abstract}
RESUMO: Trata-se de um relato de experiência sobre o uso do Ambiente Virtual de Aprendizagem (Modular Object-Oriented Dynamic Learning Environment) para a realização de um curso de atualização sobre técnicas de enfermagem e aspectos relacionados à utilização destas técnicas em situações clínicas em instituições de saúde. Participaram do curso professores, profissionais e alunos de graduação em enfermagem. São apresentadas algumas reflexões da utilização do Modular Object-Oriented Dynamic Learning Environment no processo ensino aprendizagem. Os depoimentos, postados nos fóruns, destacaram os aspectos teóricos e práticos dessa ferramenta, permitiram trocas de experiências e discussão ativa sobre as técnicas de enfermagem, tanto em seus aspectos formais, como nos aspectos relacionados ao sentimento dos envolvidos neste processo de cuidado.

PALAVRAS-CHAVE: Tecnologia educacional; Materiais de ensino; Recursos audiovisuais; Educação em enfermagem.

\section{VIRTUAL LEARNING ENVIRONMENTS AS A TOOL FOR STUDY OUTSIDE CLASS AND FOR CONTINUING EDUCATION}

ABSTRACT: This is an account of experience with the use of the virtual learning environment (Modular Object-Oriented Dynamic Learning Environment) for carrying out an updating course on techniques of nursing and aspects related to the use of such techniques in clinical situations in health institutions. Professors, health professionals and nursing undergraduates participated in the course. The article presents some reflections on the use of Modular Object-Oriented Dynamic Learning Environment in the teaching-learning process. The comments, posted in forums, highlight the theoretical and practical aspects of this tool and permitted the exchange of experiences and active discussion about the nursing techniques, as much in their formal aspects as in the aspects related to the feelings of those involved in this process of care.

KEYWORDS: Educational technology; Teaching materials; Audio-visual resources; Nursing education.

\section{AMBIENTE VIRTUAL DE APRENDIZAJE COMO HERRAMIENTA PARA EL ESTUDIO EXTRA-AULA Y EDUCACIÓN PERFECCIONADA}

RESUMEN: Este es un informe de experiencia sobre el uso del Ambiente Virtual de Aprendizaje (Modular ObjectOriented Dynamic Learning Environment) para la realización de un curso de actualización de técnicas de enfermería y aspectos asociados a la utilización de estas técnicas en situaciones clínicas en instituciones de salud. Participaron del curso profesores, profesionales y alumnos de graduación en enfermería. Son presentadas algunas reflexiones de la utilización del en Modular Object-Oriented Dynamic Learning Environment el proceso enseñanza aprendizaje. Las deposiciones publicadas en los foros destacaron los aspectos teóricos y prácticos de esa herramienta, permitieron cambios de experiencias y discusión activa sobre las técnicas de enfermería, tanto en sus aspectos formales, como en los aspectos asociados al sentimiento de los involucrados en este proceso de cuidado.

PALABRAS-CLAVE: Tecnología educacional; Materiales de enseñanza; Recursos audiovisuales; Educación en enfermería.

${ }^{1}$ Enfermeira. Doutora em Enfermagem. Professora do Curso de Graduação em Enfermagem da Universidade Estadual do Oeste do Paraná - UNIOESTE.

${ }^{2}$ Enfermeira. Mestre em Enfermagem. Professora do Curso de Graduação em Enfermagem da UNIOESTE.

Universidade Estadual do Oeste do Paraná

R. Universitária, 1619 - 85819-110 - Cascavel-PR-Brasil

E-mail: denisecostadias@gmail.com 


\section{INTRODUÇÃO}

A disponibilidade de instrumentos digitais permite novos estilos de vida e a utilização de outras técnicas de ensinar e de aprender. É inegável que o acesso a instrumentos digitais e à Internet evoluiu de forma surpreendente na última década, com o barateamento destes recursos, que são diversos e intitulados de maneiras variadas. Nesse relato, almejamos abordar o ambiente de rede digital, ou ambiente virtual de aprendizagem, e sua utilização em um curso de extensão universitária.

Ressalta-se que modernas tecnologias proporcionam novas experiências e outras formas de relação com o outro, com o conhecimento e com o processo ensino-aprendizagem ${ }^{(1)}$. A educação num ambiente de rede (ou por meio da Internet) ocorre em outro espaço e tempo. O espaço é chamado de virtual e o tempo de natureza diversa, permitindo encontros síncronos e assíncronos, possibilitando que o processo ensinoaprendizagem ocorra em diferentes locais e em diferentes momentos, de acordo com a conveniência de alunos e professores.

Em experiência com utilização de ambiente virtual de aprendizagem na área da Enfermagem, realizada em 2005, os resultados demonstram que a interatividade e a integração entre os participantes foram destaques do estudo. Dentre os aspectos positivos se ressaltou a flexibilidade do ambiente em termos de acesso ao professor e ao material, sem limites espaciais/temporais, e o registro, sob a forma de relatórios, por meio dos quais foi possível mensurar a participação dos alunos ${ }^{(2)}$.

No presente relato, optou-se por utilizar o termo Ambiente Virtual de Aprendizagem (AVA), embora existam várias denominações. De forma geral, todos indicam sistemas que sintetizam a funcionalidade de sistemas para a comunicação mediada pelo computador e métodos de entrega de material de cursos por meio da Internet ${ }^{(3)}$.

Buscando maior familiarização com as ferramentas digitais, surgiu a ideia de utilizar o AVA disponível na Universidade Estadual do Oeste do Paraná (UNIOESTE), no caso o MOODLE (Modular Object-Oriented Dynamic Learning Environment), para oferecermos um curso de atualização sobre técnicas de enfermagem e aspectos relacionados à utilização destas técnicas em situações clínicas em instituições de saúde.

O MOODLE é um AVA que foi desenvolvido pelo australiano Martin Dougiamas, em 1999(4). É voltado para aprendizagem, com ênfase em compartilhar ideias, engajar os alunos na construção do conhecimento e não, simplesmente, em distribuir informação ${ }^{(5)}$.
No ambiente virtual ou digital de aprendizagem, alunos e professores têm papel ativo, sendo que a participação de ambos no ambiente é fundamental. $\mathrm{O}$ papel do professor modifica-se uma vez que este precisa converter-se em formulador de problemas, provocador de interrogações, coordenador de equipes de trabalho e sistematizador de experiências ${ }^{(6)}$.

Assim, a proposta deste relato é descrever a experiência sobre o uso do Ambiente Virtual de Aprendizagem, no caso o MOODLE, como recurso para realização de um curso de extensão universitária sobre técnicas de enfermagem e analisar os resultados obtidos nos dois fóruns do primeiro módulo do curso.

\section{DESENVOLVIMENTO}

Foi organizado um curso de extensão universitária com carga horária de 80 horas, intitulado "Introdução de recursos didáticos no processo de ensino-aprendizagem de técnicas de enfermagem", ministrado ao longo de sete meses. Foram abordados cinco tópicos: "administração de medicamentos", incluindo aspectos relacionados à cultura da segurança para o trabalhador de enfermagem; "cuidados com as vias urinárias"; "cuidados com o aparelho digestório"; "cuidados com a pele" e "cuidados com o aparelho respiratório".

Ao formatar o curso, os recursos pedagógicos selecionados foram: fóruns de discussão, links para artigos, links para sites com materiais relacionados ao tema, links para vídeos, testes e tarefas. Considerou-se os fóruns de discussão como o recurso de maior utilidade para compartilhar ideias, trocar experiências e expor dúvidas. Optou-se pelos recursos que permitiam a modalidade assíncrona, que permitia maior flexibilidade para o acesso de todos os envolvidos.

A divulgação do curso foi feita por e-mail para os acadêmicos do curso de Enfermagem da UNIOESTE, demais escolas de graduação em Enfermagem da Cidade de Cascavel-PR, funcionários do Hospital Universitário do Oeste do Paraná, escolas de Enfermagem de universidades brasileiras e de Portugal, assim como para alguns Hospitais de Ensino.

Este curso originou-se de um projeto de pesquisa denominado com o mesmo nome, que foi aprovado pelo Comitê de Ética em Pesquisa da Universidade Estadual do Oeste do Paraná, registrado no parecer número $026 / 2007$. Foi esclarecido aos convidados que a resposta a mensagem eletrônica (e-mail), manifestando interesse em participar como avaliador e sujeito da pesquisa, seria considerada como Consentimento Livre e Esclarecido. 
Inscreveram-se no curso 143 pessoas, sendo 44 discentes, 29 enfermeiros, 13 docentes de Enfermagem, cinco farmacêuticos que interessaram-se especificamente pelo módulo de administração de medicamentos, cinco enfermeiros portugueses, e 47 pessoas que não identificaram o seu perfil profissional.

Para familiarização com o sistema, durante uma semana, os inscritos no curso participaram de um fórum de boas-vindas, relatando sua procedência, qual a experiência na área e quais eram suas expectativas quanto ao curso.

Também foi solicitado que todos se manifestassem no fórum intitulado "situação especial vivenciada por mim", descrevendo situações profissionais em que tiveram que executar procedimentos técnicos onde alguma situação inusitada ocorreu, tais como: falta de material específico, falha do material, contaminação acidental do material, resistência do paciente ou familiar para a aceitação do procedimento, entre outras situações que gostariam de compartilhar, incluindo sentimentos vivenciados. Além disso, foi solicitado aos participantes que acessassem a biblioteca e comentassem a qualidade do conteúdo bibliográfico postado, inclusive oferecendo sugestões de outros links, bem como anexar e enviar materiais adicionais, entre outros.

Durante o curso, a maior preocupação foi a de estimular a participação de todos os inscritos e, para tanto, os docentes/tutores estiveram presentes em todos os fóruns, respondendo prontamente aos questionamentos ou colocando questões para instigar reflexões sobre a temática abordada. Os docentes/tutores desempenham um papel importante nos ambientes virtuais de aprendizagem, e devem atuar como facilitadores instigando a participação, interatividade e estimulando reflexões sobre o conteúdo ${ }^{(7)}$.

Os participantes do curso relataram que as dificuldades encontradas foram de ordem técnica e pessoal. As dificuldades foram relacionadas ao cadastro e ingresso no curso, pois para a confirmação da inscrição o MOODLE envia mensagem para o $e$-mail fornecido na ficha de cadastro. Alguns servidores onde os e-mails estavam hospedados entendiam que mensagens enviadas por programas eram spam e as direcionavam para a lixeira. Por este motivo, algumas pessoas que realizaram a inscrição não conseguiram confirmá-la. Algumas ocorrências de perda da mensagem no momento de postá-las no fórum foram frustrantes para os docentes/tutores e para os participantes. Com isto. aprendeu-se a orientar a todos que, ao elaborar reflexões por escrito, seria mais prudente digitálas em documento do Word, salvá-las e, só então, colar a mensagem no fórum; assim em caso de desconexão do sistema, tem-se uma cópia de segurança.
As dificuldades de ordem pessoal foram a falta de tempo, motivo de desistência justificado por alguns participantes e a falta de familiaridade com o ambiente e com a proposta do curso. Alguns participantes tiveram dificuldade em aderir a este formato, e manifestaram que sentiram vergonha de se expor no ambiente virtual. Sobre este aspecto, pondera-se que, no ambiente presencial, algumas pessoas também têm receio de manifestar-se, geralmente por possuir uma personalidade mais introvertida. Mas, no ambiente virtual, talvez o motivo não seja apenas a timidez, mas a dificuldade para transformar sua reflexão em texto.

Desde muito cedo, a criança, imersa num dado meio social, aprende e utiliza a linguagem oral, processo este, que será indispensável para a aprendizagem da leitura e escrita. No entanto, ler é uma atividade linguística formal e sua aprendizagem requer o desenvolvimento de uma consciência conhecedora das estruturas linguísticas que deverão ser manipuladas intencionalmente ${ }^{(8)}$. Assim, atividades que desenvolvam a leitura e a escrita são fundamentais ao longo de todo o processo educativo, visando o desenvolvimento de habilidades que preparem o indivíduo para momentos posteriores. A partir do terceiro mês do curso, verificou-se diminuição do número de participantes, assim como do número de mensagens nos fóruns. Mas a qualidade das contribuições continuou relevante.

Houve um esforço contínuo para estimular o diálogo, encaminhando semanalmente mensagens aos participantes, buscando uma forma acolhedora de comunicação, mesmo que por meio da redação de mensagens postadas em uma "tela". No entando, isto representou uma sobrecarga de trabalho aos docentes/tutores.

As funções de docente/tutor, nesta modalidade educacional, exige tempo e energia pessoal, e requer coragem profissional. No espaço virtual há maior flexibilidade para o aluno, mas não para o tutor, que muitas vezes, por falta de apoio institucional, tem trabalhado na AVA muito mais do que no ensino convencional, seja na parte técnica, na abordagem do conteúdo, nas discussões e no acompanhamento dos alunos ${ }^{(9)}$.

\section{CONSIDERAÇÕES FINAIS}

Configura-se um desafio o desenvolvimento de atividades que possam ser igualmente atraentes para pessoas com perfis tão diferenciados como os participantes deste curso de extensão. Esta diversidade de perfis traz a vantagem da troca de experiências, na qual aqueles que estão se iniciando ganham muito quando compartilham com os mais expe- 
rientes. Também para os docentes/tutores foi interessante ler as mensagens com relatos de alunos, suas dificuldades e ansiedades em relação ao aprendizado das técnicas.

De maneira geral, os depoimentos postados nos fóruns contribuíram com aspectos teóricos e práticos, permitiram trocas de experiências e discussão ativa sobre as técnicas de enfermagem, tanto em seus aspectos formais como nos aspectos emocionais dos envolvidos neste processo de cuidado.

Vislumbra-se que as situações que hoje constituem barreiras tendem a ser reduzidas no futuro, pois a tendência é uma maior familiarização com as ferramentas e ambientes virtuais de aprendizagem e consequente aprimoramento de seu uso.

\section{REFERÊNCIAS}

1. Azevedo W. Muito além do jardim de infância: o desafio do preparo de alunos e professores on-line. In: Congresso Internacional de Educação a Distância. 1998 [acesso em 10 mai 2010]. Disponível: http://www.abed. org.br/antiga/htdocs/paper_visem/wlson_azevedo.htm

2. Telles Filho P, Cassiani SHB. Implementação e avaliação do módulo à distância "administração de medicamentos” Cogitare Enferm. 2007;12(2):222-8.

3. Dias DC. Educação sem distâncias: utilização do WebCT como ferramenta de apoio para o ensino da terapia intravenosa na graduação de enfermagem [tese]. Ribeirão Preto (SP): Universidade de São Paulo; 2003.

4. Amaral EMH, Prass FS, Falkembach GAM, Flores, MLP. Moodle como apoio às disciplinas presenciais. Jornada de Pesquisa e Extensão [Internet]. Santa Maria (RS): ULBRA, 2009. [acesso em 05 fev 2010] Disponível: http://www.ulbra.br/santamaria/eventos/ jornada/2009/JPE2009/_final_Sis1257881833.pdf

5. Farbiarz A, Farbiarz J. Reflexão acerca do design de ambientes virtuais de aprendizagem. Tríades em Revista. [Internet] 2008 [acesso em 20 maio 2010]. Disponível: http://publique.rdc.puc-rio.br/triades/ media/Farbiarz_vol0_n0.pdf

6. Camacho ACLF. Análise das publicações nacionais sobre educação à distância na enfermagem. Rev Bras Enferm 2009;62(4):588-93.

7. Dias DC, Cassiani SHB. Educação de enfermagem sem distâncias: uma ruptura espaço/temporal. Rev Esc Enferm USP. 2004;38(4):467-74.
8. Maluf MR, Zanella MS, Molina PKSM. Habilidades metalinguísticas e linguagem escrita nas pesquisas brasileiras. Bol Psicol. [Internet] 2006;LVI(124) [acesso em 25 maio 2011]. Disponível: http://pepsic.bvsalud.org/ pdf/bolpsi/v56n124/v56n124a06.pdf

9. Moraes RA. Aula virtual e democracia. [acesso em 15 maio 2009]. Disponível: http://www.abed.org.br/ seminario2006/pdf/tc004.pdf 